\title{
FEIRAS DE MATEMÁTICA: UM PROJETO DE EXTENSÃO QUE BUSCA A MELHORIA DO ENSINO E DA APRENDIZAGEM DE MATEMÁTICA
}

\author{
MATH FAIRS: AN OUTREACH PROJECT THAT AIMS THE \\ IMPROVEMENT OF TEACHING AND LEARNING MATH
}

Viviane Clotilde da Silva** Janaína Poffo Possamai**

\section{RESUMO:}

Este artigo descreve o movimento das Feiras de Matemática como um projeto de extensão, que possibilita acões relacionadas à pesquisa e ao ensino e tem como objetivo apresentar histórico das Feiras de Matemática, suas concepções e seu movimento de expansão, bem como discutir a avaliação da XXXIV Feira Catarinense de Matemática. Para essa avaliacão, foram utilizados como instrumento de coletas de dados questionários com questões fechadas e abertas, respondidos por professores orientadores, alunos expositores e visitantes que participaram da Feira. Os resultados indicam que os objetivos de realização da Feira de Matemática, segundo as concepções históricas que norteiam esse movimento, estão sendo alcançados, contribuindo com a melhoria da aprendizagem matemática e da formação do professor.

Palavras-chave: Educação Matemática; Ensino e aprendizagem; Gestão de Feiras.

\begin{abstract}
:
This article describes the movement of Math Fairs as an outreach project, which provides actions related to research and teaching in addition to presenting the history of Math Fairs, their conceptions and their expansion movement, as well as the evaluation of the 34th Catarinense Math Fair. To evaluate the project the data collection included questionnaires with closed and open questions, answered by supervising teachers, students and visitors that participated of the Fair. The results indicate that the aims of the Math Fair, according to the historical conceptions that guide this movement, are being achieved, contributing to the improvement of mathematics learning and teacher education.
\end{abstract}

Keywords: Mathematical Education; Teaching and learning; Management of Fairs. 


\section{Introdução}

O projeto Rede de Feiras de Matemática (RFMat), da Universidade Regional de Blumenau busca desenvolver a extensão como uma via de mão dupla, trabalhando em parceria com a sociedade, em que ambos contribuem e aprimoram seus conhecimentos. Desta forma, nestes 34 anos de existência,

[... surgiram lideranças, desenvolveu-se a capacidade de diagnosticar, de auto-organização e gestão, de equacionar e resolver situaçõesproblemas[sic], de criar consciência quanto aos fatores de sucesso ou fracasso e obter reação positiva diante deles. (ZERMIANI, 2003, p. 125).

Em relação ao tripé extensão-ensino-pesquisa, pode-se afirmar que este projeto de extensão tem relação com a pesquisa na medida em que incentiva o processo de investigação nas salas de aula e também pelo fato de proporcionar o desenvolvimento de pesquisas acadêmicas relacionadas ao ensino de Matemática, com o desenvolvimento de vários estudos de iniciação científica, mestrado e doutorado sobre este tema. Desta forma, busca-se fazer com que a pesquisa e a extensão se desenvolvam de forma conjunta, evitando "a elitização verificada em determinados meios acadêmicos, caracterizada pela distância entre os pesquisadores educacionais e o seu objeto de pesquisa (estudantes da Educação Básica)" (ZERMIANI, 2003, p. 126).

No que se refere à relação com a pesquisa e ensino, o movimento das Feiras de Matemática incentiva, acompanha e avalia trabalhos de ensino desde a Educação Infantil até o Ensino Superior, incluindo a Educacão Especial, com o intuito de contribuir com a melhoria dos processos de ensino e de aprendizagem. Nesse processo, os professores são incentivados a pesquisar a sua própria prática e, por meio dela, possibilitar que a Matemática desenvolvida em suas salas de aula seja fruto de um processo de construção dos estudantes.

Este processo se torna cíclico, uma vez que muitas pesquisas desenvolvidas na universidade chegam aos professores da Educação Básica e os auxiliam em suas práticas que, por sua vez, por meio dos resultados obtidos e apresentados nas Feiras, retornam ao ensino superior, sendo explorados em disciplinas dos cursos de Licenciatura em Matemática e de Licenciatura em Pedagogia, contribuindo para formação destes futuros profissionais.

As Feiras de Matemática se constituem em um evento que traz como princípio fundamental a colaboração em detrimento da competição, a formação continuada, a constante socialização do que está sendo desenvolvido em Educação Matemática nas escolas e o foco no conhecimento compartilhado (OLIVEIRA; PIEHOWIAK ZANDAVALLI, 2015, p. 46).

Importante salientar que as Feiras de Matemática $^{1}$ são desenvolvidas com os seguintes objetivos:

a) Despertar nos alunos maior interesse na aprendizagem da Matemática; b) Promover o intercâmbio de experiências pedagógicas e contribuir para a inovação de metodologias; c) Transformar a Matemática em ciência construída pelo aluno e mediada pelo professor; d) Despertar para a necessidade da integração vertical e horizontal do ensino da Matemática; e) Promover a divulgação e a popularização dos conhecimentos matemáticos, socializando os resultados das pesquisas nesta área; f) Integrar novos conhecimentos e novas tecnologias de informação e comunicação aos processos de ensino e aprendizagem (SILVA, 2014, p. 194-195).

Este projeto tem ampla aceitação da comunidade educacional, uma vez, que em 2018, completou 34 anos de existência, sendo executado de forma colaborativa por várias instituições de ensino do estado de Santa Catarina.

Este artigo visa trazer uma breve apresentação da história das Feiras de Matemática, dos seus aspectos fundamentais e o processo de avaliação da e na mesma.

\section{As Feiras de Matemática: início e aspectos fundamentais}

No início da década de 1980, foi criado, na Universidade Regional de Blumenau - FURB, o Laboratório de Matemática da FURB (LMF), que visava auxiliar na melhoria do ensino de Matemática, na época considerado tradicional e livresco. Para isso, este laboratório promovia cursos, desenvolvia oficinas e materiais com e para professores de matemática da Educação Básica à Superior. Em 1985, os professores que trabalhavam neste mesmo laboratório desenvolveram um projeto de extensão universitária denominado Feiras de Matemática, cujo objetivo era promover um evento onde "professores que desenvolvessem metodologias inovadoras para 0 ensino da Matemática em sala de aula pudessem apresentá-las e discuti-las, incentivando outros professores a procederem dessa forma em suas salas de aula" (SILVA, 2014, p. 189).

Naquele ano, foram realizadas a I Feira Regional e a I Feira Catarinense de Matemática, onde foram apresentados, em cada evento, 30 trabalhos, que tinham como objetivos: "despertar, nos alunos, maior interesse pela aprendizagem de matemática; proporcionar maior integração da matemática com as demais disciplinas; promover intercâmbio de experiências pedagógicas" (ZERMIANI, 2002, p.53). $\mathrm{O}$ número de trabalhos apresentados não foi expressivo, mas, mesmo assim, gerou grande repercussão na comunidade educacional. É possível observar isso no depoimento apresentado por uma professora que participou destas Feiras nas narrativas de Silva (2014, p. 216):

\begin{abstract}
Quanto à relação entre as Feiras e o ensino, eu acho que ela contribuiu bastante. Eu, como professora, vejo alunos que foram comigo a uma Feira. Depois eles entram no Ensino Médio e lá estão eles na Feira de novo. Eu sempre dizia pra eles: 'Quando tu vais a uma coisa, quando tu tomas gosto, então aquela coisa acontece'. Então eu acho que, para o ensino, a avaliação geral é que ela tem contribuído. Sempre contribuiu
\end{abstract}

A segunda versão destas Feiras foi realizada logo no ano seguinte, sendo que a Catarinense aconteceu em outra região do estado. Com o passar dos anos, várias regiões do estado de Santa Catarina começaram a também desenvolver Feiras Regionais de 
Matemática e as Feiras Catarinenses aconteceram cada ano em um município diferente, buscando envolver professores de todas as regiões do Estado.

O envolvimento, a participação e a colaboração de todos os envolvidos - coordenadores, professores orientadores e estudantes, de vários níveis e redes de ensino - em prol da melhoria do processo de ensino, em busca de uma aprendizagem matemática com significado $^{2}$, solidificou este projeto e fez com que a Mostra/Feira, momento em que acontece a exposição dos trabalhos, se tornasse um período de troca de experiências, formação para professores e estudantes.

Devido à expansão, este projeto extrapolou as fronteiras de uma única instituição organizadora $\mathrm{e}$ passou a ser desenvolvido, em Santa Catarina, de forma colaborativa, através de uma comissão formada por professores da FURB, dos Institutos Federais Catarinense - IFC e de Santa Catarina - IFSC, Universidade Federal de Santa Catarina - UFSC, campus de Blumenau, de diversas gerências de ensino do Estado e secretarias municipais de educação.

Em 2015, foi assinado um convênio interinstitucional entre a FURB, o IFC, a Universidade do Estado da Bahia - UNEB (que começou a coordenar Feiras de Matemática em 2006, na Bahia) e a Sociedade Brasileira de Educação Matemática SBEM, com o objetivo de expansão das Feiras de Matemática para outros estados da federação.

Buscando que este projeto tenha continuidade, os integrantes procuram respeitar as concepções das Feiras de Matemática - construídas de forma colaborativa - e aprimorá-lo, ano a ano, em cinco aspectos: Inclusão Social, Formação de Estudantes e Professores, Ampliação no número de Envolvidos, Ambientes Diferenciados de Aprendizagem e Qualidade na Educação Escolar (ZERMIANI, 2017).

A Inclusão Social no projeto Rede de Feiras de Matemática ocorre com o incentivo para a participação de estudantes com deficiência (deficiências sensoriais, mentais, altas habilidades ou dificuldades de aprendizagem). Com relação à inclusão dos alunos com dificuldade de aprendizagem, a proposta das Feiras sempre foi o desenvolvimento de práticas educativas diferenciadas em sala de aula, envolvendo todos os estudantes, criando oportunidade para que todos aprendam matemática com compreensão. O crescimento no número de trabalhos apresentados que, mesmo sendo desenvolvido em salas de aula do ensino regular, envolvam materiais ou propostas que incluem estudantes com deficiência, em muitos casos eles mesmos expõem os trabalhos mostrando a forma que participam da dinâmica da aula e o que eles aprenderam.

Uma das categorias que compõem a inscrição de trabalhos nas Feiras de Matemática é denominada Educação Especial, na qual são apresentados projetos que envolvam matemática e que sejam desenvolvidos em salas de atendimentos especializados, realizados em sala multifuncionais ou de escolas voltadas à Educação Especial (SOUZA, 2016).

Nesse contexto, procurou-se aprimorar os espaços e processos para melhor atender estes estudantes nas Feiras de Matemática, de modo que na ficha de inscrição o professor orientador deve identificar o aluno expositor que possui uma deficiência e qual é, para que os coordenadores possam melhor adaptar o espaço disponibilizado para este trabalho (longe de sons externos, caso haja um aluno deficiente visual, para que possa melhor ouvir os que se dirigem a ele; um espaço físico maior, caso haja um cadeirante, etc). Há uma ficha de avaliação especial para os trabalhos e os professores avaliadores recebem instruções especiais sobre o processo de avaliação.

A Formação, neste processo, acontece tanto de modo formal como informal. Formalmente acontece por meio de cursos de aperfeiçoamento realizados anualmente, em várias cidades do estado e durante os Seminários de Avaliação e Gestão das Feiras de Matemática (que já está na sexta edição, com publicação dos Anais $^{3}$ ), que acontecem com a participação de estudantes e professores de todo estado e de outros estados da federação, que também já estão desenvolvendo Feiras de Matemática, de acordo com os princípios das Feiras de Santa Catarina.

Nesse aspecto, é importante ressaltar o princípio geral $^{4}$ que norteia as Feiras de Matemática:

\begin{abstract}
A Feira de Matemática é um programa de incentivo ao estudo e pesquisa pelos estudantes (de todas as fases de escolaridade) sob a orientação de professores nos espaços e períodos escolares e de socialização desses estudos e pesquisa à comunidade por meio de uma exposição. (BIEMBENGUT; ZERMIANI, 2014, p. 52)
\end{abstract}

Ainda, busca-se anualmente a Ampliação do número de envolvidos com as Feiras, seja de professores e instituições nas cidades já participantes ou de cidades que ainda não participam. Esta busca se desenvolve na formação de professores e reuniões com dirigentes educacionais. Nestes encontros com professores, procura-se conscientizar sobre a necessidade de uma prática diferenciada, buscando maior participação dos estudantes e uma aprendizagem com significado. Também se ressalta a importância de apresentar seus trabalhos em um evento onde há troca de experiências (processo que já vem ocorrendo). Junto aos dirigentes educacionais, busca-se a ampliação do número de municípios e estados na participação da Rede Feiras de Matemática, mostrando-se a importância do desenvolvimento de um evento que busca a valorização de uma educação matemática acessível a todos.

Em relação aos Ambientes Diferenciados de Aprendizagem, eles envolvem tanto o momento da exposição quanto o desenvolvimento dos trabalhos. $\mathrm{Ou}$ seja, a Feira de Matemática se configura como um movimento que se desenvolve ultrapassando o momento de exposição, da mostra de trabalhos, e contempla um ciclo de desenvolvimento do trabalho, exposição e socialização, e, por fim, continuidade e melhoria do trabalho com base nas avaliações recebidas. Os trabalhos apresentados nas Feiras de Matemática muitas vezes não se limitam as fronteiras da sala de aula, sendo desenvolvidos em lugares diversos, apresentando realidades físicas e sociais diversificadas.

Desta forma, mostram que é possível, em muitas situações, ensinar matemática explorando os conceitos a partir do estudo do entorno das escolas e da realidade de cada aluno. Os envolvidos na organização das Feiras de Matemática incentivam este tipo de trabalho, 
acreditando que ele tende a produzir uma aprendizagem com maior significado para os alunos, uma vez que busca explorar os conceitos científicos desenvolvidos na escola a partir dos conhecimentos e conceitos espontâneos ${ }^{5}$ dos estudantes (VYGOTSKY, 2000).

Além disso, a própria exposição de trabalhos se apresenta como um ambiente informal de formação, tanto dos estudantes que têm a possibilidade de ver os conteúdos por eles estudados serem abordados de outra forma, quanto dos professores que aproveitam para conhecer o trabalho de outros docentes e trocar experiências, buscando inspiração para a sua própria prática.

[...] um espaço de formação de professores e alunos, na medida em que os participantes concebem trabalhos, os elaboram, os executam e os apresentam, explicitando neles e por meio deles as concepções que regem suas práticas escolares. Por fim, as Feiras e os trabalhos apresentados se refletem na comunidade que, com as visitas, acessa, de algum modo, as escolas e suas práticas, compartilhando fazeres (SILVA, 2014, p. 198-190).

Em relação ao momento de exposição, a Feira se constitui como espaço formativo. $\mathrm{Na}$ sequência, o depoimento de duas professoras que participaram de Feiras de Matemática confirmam:

[...] Eu adorava as Feiras de Matemática pelo seguinte: eu podia passar em outros estandes e aprender coisas diferentes, que eu levava para sala de aula depois. As Feiras foram reensinando, reaprendendo e me motivando para cada vez entrar em outra Feira, porque, querendo ou não, elas me motivavam a entrar em outra. A troca de ideias é muito grande. $\mathrm{O}$ que você traz de conhecimento, de bagagem, de coisas novas... 'Nossa, mas eu trabalhava aquilo e não imaginava que pudesse fazer da maneira que aquela professora fez.' Essas trocas são fundamentais para o professor. (SILVA, 2014, p. 190)

[...] você aprende muito com isso. Você vê, eu sempre ficava ouvindo o trabalho dos outros. Pegava muita coisa do que tinha. 'Ah! Isso aqui deu certo, posso adaptar na minha escola, acho que vale a pena'. Para a criança que participa é uma experiência que eles não esquecem. Muito bom! (SILVA, 2014, p. 217)

Desta forma, é possível verificar que a Rede de Feiras de Matemática não se restringe a um evento, mas se tornou parte do processo de ensino de Matemática, uma vez que se pode dizer que ela inicia quando o professor orientador prepara suas aulas e, dependendo do andamento do mesmo, inscreve (ou não) essa prática em uma Feira de Matemática.

Durante a Mostra/Feira, os trabalhos recebem uma avaliação descritiva que tem o objetivo de fornecer ao professor condições de continuidade. Assim, após as Feiras, o professor tem possibilidade de aprimorar e aprofundar o estudo desenvolvido e apresentado e, além disso, adquirir ideias para o desenvolvimento de novos trabalhos a partir das experiências trocadas durante o evento.

A busca pela Qualidade da Educação Escolar acontece durante as formações relacionadas a este projeto. Nestes encontros, se procura levar o professor a ver o "erro" como uma etapa do processo de ensino e aprendizagem, pois é por meio dele que o professor pode verificar quais as lacunas no entendimento do aluno e, também, se incentiva o uso de metodologias diversas para que o professor possa preparar sua prática com o olhar voltado para realidade em que ele está inserido, de forma a desenvolver sua prática, estimulando o aluno na construção do seu conhecimento.

Para que estes aspectos sejam sempre primados, é necessário que o projeto Rede de Feiras tenha um sistema de avaliação da e na Feira bem desenvolvido, que garanta a gestão participativa e dê fundamentos para a sua continuidade. $\mathrm{Na}$ sequência, será descrita a metodologia das avaliações que ocorrem neste projeto.

\section{Metodologia de Avaliação das Feiras de Matemática}

A avaliação desse movimento é desenvolvida em vários momentos, analisando os aspectos organizacionais, tendo como objetivo a continuidade do evento.

O processo avaliativo acontece em momentos distintos. No dia da exposição dos trabalhos, acontecem: (1) no final, por meio de uma assembleia na qual podem participar todos os participantes diretos da Feira - alunos expositores, professores orientadores, professores avaliadores e dirigentes educacionais - que fazem parte da Comissão Central Organizadora; (2) durante, por meio da aplicação de um questionário respondido por todos os participantes diretos e mais os visitantes. Os questionários são elaborados com perguntas de múltipla escolha e perguntas abertas. Algumas avaliações também são obtidas informalmente, por meio de diálogos presenciais e via e-mail.

Além desta avaliação anual, são realizados Seminários específicos de Avaliação destes eventos, abertos ao público educacional e que discutem todos os processos envolvidos nas Feiras: orientação, avaliação, exposição e organização.

Após as Feiras, as respostas obtidas nos questionários são contabilizadas e analisadas junto com as questões levantadas na assembleia e redigidas em uma Ata. Os resultados obtidos são discutidos no ano seguinte, na primeira reunião da Comissão Central de Organização, quando se inicia a preparação da próxima Feira de Matemática.

$\mathrm{Na}$ sequência, apresentam-se os resultados dos questionários respondidos pelos expositores, professores orientadores e visitantes da XXXIV Feira Catarinense de Matemática, juntamente com a análise de cada questão.

\section{Avaliação da XXXIV Feira Catarinense de Matemática}

A XXIV Feira Catarinense de Matemática foi realizada em outubro de 2018, no município de Massaranduba (SC), e foram aplicados questionários de caráter quantitativo e qualitativo para coletar informações acerca das ações desenvolvidas durante a Feira e o impacto proporcionado para o ensino de Matemática na região. As ações propostas nas Feiras 
foram avaliadas por três grupos: expositores, professores orientadores e visitantes. A análise dos principais dados obtidos na aplicação dos questionários, feita a partir dos objetivos traçados para este evento, estão apresentadas a seguir.

\section{a) Questionário respondidos por Expositores}

$\mathrm{Na}$ avaliação aplicada aos expositores, foram constatadas as seguintes informações sobre a participação em Feiras de Matemática e sobre o desenvolvimento dos trabalhos apresentados:

- Aproximadamente $80 \%$ dos expositores avaliados já haviam participado de uma ou mais edições anteriores das Feiras de Matemática.

- Aproximadamente $41 \%$ dos trabalhos apresentados foram desenvolvidos durante as aulas, com todos alunos da turma.

- Aproximadamente $41 \%$ dos trabalhos apresentados foram desenvolvidos em atividades aulas extraclasse.

- Aproximadamente $12 \%$ dos trabalhos apresentados foram desenvolvidos extraclasse com alguns alunos, no formato de trabalho de pesquisa em equipe.

- Aproximadamente $6 \%$ dos trabalhos foram desenvolvidos de outras maneiras, envolvendo alunos de turmas e anos diferentes, aplicando materiais didáticos em outras turmas, entre outras formas.

Estas respostas mostram que quase metade dos trabalhos apresentados na Feira foram desenvolvidos exclusivamente em sala, durante a aula de matemática, mas, devido ao reduzido número de aulas, muitos professores mesclam a atividade em sala com atividades extraclasse, onde os alunos desenvolvem pesquisas e constroem materiais. Importante é que a maioria envolve todos aos alunos da classe, de modo a desenvolver um ensino de matemática para todos, que é um dos objetivos das Feiras.

Os resultados deste questionário também apontam para uma realidade que vem aparecendo nos últimos anos, a apresentação de trabalhos de pesquisa desenvolvidos por estudantes de mesma série/ano letivo ou até mesmo de séries/anos diferentes e orientados por um professor de matemática.

As respostas indicam que as Feiras estão conseguindo atingir o objetivo de "Transformar a Matemática em ciência construída pelo aluno e mediada pelo professor".

Sobre os ganhos dos expositores durante o processo de desenvolvimento do trabalho apresentado e a participação na Feira, obtiveram-se os seguintes resultados:

- Aproximadamente 15,5\% dos expositores relataram ter melhorado a interação com os demais colegas.

- Aproximadamente 15,3\% dos expositores afirmaram que adquiriram mais gosto pela Matemática.
- Aproximadamente 39,2\% dos expositores declararam que obtiveram maior aprendizagem de conteúdos matemáticos.

- Aproximadamente 25,2 \% dos expositores disseram ter adquirido maior confiança em relação ao aprendizado de Matemática.

- Aproximadamente $4,8 \%$ dos expositores citaram outros ganhos, como conhecimento de outras áreas (Física e Astronomia), menos timidez, entre outros aspectos.

As respostas mostram que, segundo os próprios estudantes, sua relação com a Matemática melhorou qualitativamente. Observando as respostas, é possível verificar que a maior parte dos estudantes assinalou a melhoria da aprendizagem como maior ganho do processo de desenvolvimento e apresentação dos trabalhos, mostrando que o objetivo "Despertar nos alunos maior interesse na aprendizagem da Matemática" está sendo atingido. Outro ponto a ser destacado é que, segundo um quarto dos estudantes que responderam o questionário, a participação no processo das Feiras proporcionou-lhes maior confiança para atuar como protagonistas no seu processo de aprendizagem matemática.

$\mathrm{Na}$ sequência, apresentam-se alguns relatos de expositores sobre o motivo que os levaram a participar das Feiras de Matemática. Estes relatos foram escolhidos por representarem os pontos apresentados pela maioria.

Expositor 1: "O desenvolvimento de nosso trabalho possibilitou nossa participação na feira, tendo como principal objetivo mostrar aos professores um método mais simples de ensinar Matemática. Usamos o software GeoGebra que é de fato muito bom para as aplicações feitas. Relacionamos Matemática com biologia".

Expositor 2: "Após um trabalho desenvolvido na aula de artes juntamente com matemática, onde foi desenvolvido um trabalho sobre música e nos despertou interesse na feira".

Expositor 3: "Interesse, empolgação e apoio da professora e da familia".

Expositor 4: "Aprender conteúdos matemáticos de uma forma lúdica e divertida".

Expositor 5: "Poder mostrar que os conceitos matemáticos também são utilizados em outras áreas, como na natureza".

Expositor 6: "A divulgação do projeto, tendo em vista que além da redução de gastos financeiros, também é importante para o meio ambiente, porque é fundamental adotarmos medidas como estas e incentivar outros a fazerem o mesmo".

Observa-se que o motivo da participação destes alunos foi a possibilidade de apresentar o trabalho desenvolvido durante as aulas de matemática. Outra questão que é possível observar nas respostas é que alguns desses trabalhos são desenvolvidos envolvendo 
outras áreas do conhecimento, buscando apresentar aos estudantes a relação entre a matemática e outras áreas, assim como levando-os a atribuir sentido ao conhecimento adquirido.

\section{b) Questionário respondidos por Professores Orientadores}

Das informações coletadas a partir dos questionários aplicados com os professores orientadores, seguem algumas informações obtidas:

- Aproximadamente $90 \%$ dos professores orientadores já haviam participado de uma ou mais edições anteriores das Feiras de Matemática. Destas participações, 39,3\% foram como professor orientador, $9,8 \%$ como expositor, $11,6 \%$ como visitante, $37,5 \%$ como avaliador e $1,8 \%$ na organização.

- Aproximadamente $23,4 \%$ dos professores orientadores afirmaram que o desenvolvimento do trabalho e a participação na Feira lhes proporcionaram aumento da autoestima.

- Aproximadamente $24 \%$ dos professores orientadores colocaram que o processo de desenvolvimento do trabalho e a participação na Feira lhes proporcionaram melhor postura pedagógica.

- Aproximadamente 21,6\% dos professores orientadores colocaram que o processo de desenvolvimento do trabalho e a participação na Feira lhes proporcionaram melhores perspectivas de projeção profissional.

- Aproximadamente $29,8 \%$ dos professores orientadores colocaram que o processo de desenvolvimento do trabalho e a participação na Feira lhes possibilitaram trocar experiências com outros professores e comunidade.

- Aproximadamente 99\% dos professores orientadores tiveram suas expectativas atendidas.

As respostas apresentadas pelos professores orientadores mostraram que o evento Feiras de Matemática têm lhes auxiliado em suas práticas pedagógicas, uma vez que as respostas assinaladas indicam que o desenvolvimento do trabalho contribuiu para aumento da autoestima e melhoria na postura pedagógica. Inclusive, os professores ressaltaram que as Feiras proporcionaram troca de experiência, reforçando o caráter das mesmas como um espaço de formação de professores. Importante ressaltar o último ponto apresentado, que quase $100 \%$ declararam que a Feira de Matemática atendeu às suas expectativas.

\section{c) Questionário respondidos por Visitantes}

$\mathrm{Na}$ aplicação dos questionários aos visitantes da Feira, constatou-se que aproximadamente $90 \%$ dos visitantes possuem idade inferior a 30 anos e são membros da comunidade escolar ou familiares dos estudantes expositores. Isto mostra que o grande público visitante das Feiras se constitui de escolas da região onde elas acontecem, além de que as Feiras estão atendendo ao objetivo traçado de "Promover a divulgação e a popularização dos conhecimentos matemáticos, socializando os resultados das pesquisas nesta área" (SILVA, 2014, p. 194).

Dos visitantes que aceitaram responder $o$ questionário proposto, aproximadamente 44,7\% responderam que a qualidade da Feira e dos trabalhos expostos estava excelente, $29,8 \%$ que a qualidade foi ótima e $25,5 \%$ que a qualidade de ambos foi boa, justificando, na maior parte dos casos, pela organização, empenho dos envolvidos, bom preparo dos expositores, variedade de trabalhos e temas, entre outras características relacionadas.

\section{Considerações Finais}

O Projeto Rede de Feiras de Matemática (PRFMat) tem como objetivo, através da organização e gestão das Feiras de Matemática em âmbito municipal, regional, estadual e nacional, aprimorar a qualidade do ensino de matemática na educação básica, na educação especial e no ensino superior.

O PRFMat, em 2018, promoveu 1 Feira Municipal, 1 Feira Regional, 1 Feira Estadual e 1 Feira Nacional, além de prestar assessoria às demais feiras realizadas em âmbito regional, envolvendo diretamente cerca de 700 estudantes e 700 professores do ensino básico, especial e superior da rede pública e privada. Considerando que cada um dos trabalhos tenha sido desenvolvido em sala de aula, com uma média de 30 alunos, e que cada aluno tenha compartilhado sua experiência com pelo menos mais uma pessoa, estimam-se 11.200 pessoas, entre estudantes, professores e familiares, foram envolvidas indiretamente nas ações do projeto durante o ano.

Os bolsistas acadêmicos participantes agregaram, em sua formação, acadêmica a vivência em ambientes e realidades diferentes daqueles apresentados em sala durante as disciplinas de sua grade curricular e também foram oportunizados a trocar e adquirir experiências com professores e alunos da Educação Básica. A experiência vivida se faz importante diante da reflexão sobre o papel da sua profissão na sociedade, possibilitando, assim, a formação de profissionais capacitados para lidar com os problemas emergentes da atualidade.

Os trabalhos apresentados nas Feiras possibilitaram a socialização de aproximadamente 350 trabalhos oriundos de práticas de sala de aula que objetivam proporcionar recursos pedagógicos que auxiliem o processo de construção e reconstrução do ensino de Matemática. Deste modo, professores podem aprimorar práticas pedagógicas inovadoras para suas aulas, contribuindo, assim, com o desenvolvimento da educação nacional. 


\section{Notas}

${ }^{1}$ Informações sobre as Feiras de Matemática estão disponíveis em www.furb.br/lmf e www.sbembrasil.org.br/feiradematematica

2 Entende-se por uma aprendizagem com significado aquela em que o estudante avança além do saber, de conhecer informações, é mais do que ser capaz de seguir um procedimento ou utilizar um algoritmo, e acontece quando o estudante tem a capacidade de justificar por que uma resposta é correta ou porque uma regra matemática faz sentido (VAN DE WALLE, 2009).

${ }^{3}$ Anais dos Seminários disponíveis em:

http://www.sbembrasil.org.br/feiradematematica/anais.html.

Acesso em: 10 dez. 2018

${ }^{4}$ Os princípios específicos estão descritos em BIEMBENGUT, M. S.; ZERMIANI, V. Feiras de Matemática: História das ideias e ideias da história. Blumenau: Nova Letra, 2014. 264 p.

5 Segundo Schroeder (2013, p. 133), conceitos espontâneos são aqueles que "têm sua gênese empírica nas situações cotidianas e concretas vividas pelo sujeito".

\section{Referências}

BIEMBENGUT, M. S.; ZERMIANI, V. Feiras de

Matemática: História das ideias e ideias da história.

Blumenau: Nova Letra, 2014. 264 p.

OLIVEIRA, F.P.Z. de; PIEHOWIAK, R.; ZANDAVALLI, C. Gestão das Feiras de Matemática: em movimento e em rede. In: HOELLER, S.A. de O. et al. Feiras de Matemática: percursos, reflexões e compromisso social. Blumenau: Ifc, 2015. p. 32-47.

SCHROEDER, E. Os Conceitos Espontâneos dos estudantes como referencial para o planejamento de aulas de Ciência: análise de uma experiência didática para o estudo dos répteis a partir da teoria histórico cultural do desenvolvimento. Experiências em Ensino de Ciências, v. 8, n. 1, 2013. p. 130-144. Disponível em:

http://if.ufmt.br/eenci/artigos/Artigo_ID205/v8_n1_a2013.p df. Acesso em: 25 abr. 2019.
SILVA, V.C. da. Narrativas de professoras que ensinam Matemática na região de Blumenau (SC): sobre as feiras Catarinenses de Matemática e as práticas e concepções sobre ensino e aprendizagem de matemáticas. 2014. $322 \mathrm{f}$. Tese (Doutorado em Educação para a Ciência) Faculdade de Ciências, Universidade Estadual Paulista, Bauru, 2014. Disponível em: https://repositorio.unesp.br/bitstream/handle/11449/111156/ 000794827.pdf? sequence $=1$ \&isAllowed $=\mathrm{y}$. Acesso em: 17 fev. 2019.

SOUZA, C. P. Educação Especial: as Feiras como espaço de inclusão. Boletim SBEM Especial 'Feiras de Matemática', site SBEM, p. 28-30, 01 jun. 2016

VAN DE WALLE, J. A. Matemática no Ensino

Fundamental: Formação de Professores e Aplicações em Sala de Aula. 6. ed. Porto Alegre: Artmed, 2009.

VYGOTSKY, L. S. A construção do pensamento e da linguagem. São Paulo: Martins Fontes, 2001.

ZERMIANI, V. J. Avaliação dos projetos de Extensão Desenvolvidos pelo Laboratório de Matemática da FURB. Dissertação (Mestrado em Educação) Universidade Regional de Blumenau. Blumenau, 2002.

ZERMIANI, V. J. Feiras de Matemática de Santa

Catarina: relevância para a educação. Blumenau: Edifurb, 2003.

ZERMIANI, V.J.; BREUCKMANN, H. J. Gestão e Organização de uma Feira de Matemática. Blumenau, 2008. 74 p.

ZERMIANI, V.J. Trajetória da Rede de Feiras de Matemática: 33 anos. In: SEMINÁRIO NACIONAL DE AVALIAÇÃO E GESTÃO DAS FEIRAS DE MATEMÁTICA, 6., 2017. Anais... Camboriú, 2017. p. 252265. Disponível em:

http://proxy.furb.br/soac/index.php/feirasMat/pub/paper/vie wFile/3606/942. Acesso em: 18 out. 2018. 